\title{
Hospitalizations due to Angioedema without Urticaria in a Portuguese Center: Five Year Retrospective Study
}

\author{
Internamentos por Angioedema sem Urticária num \\ Centro Hospitalar Português: Estudo Retrospetivo \\ de Cinco Anos
}

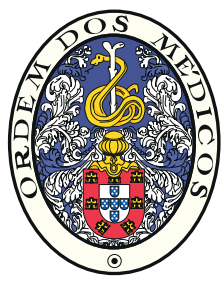

\author{
Joana COSME $\triangle^{1}$, Amélia SPÍNOLA ${ }^{1}$, Manuel Branco FERREIRA ${ }^{1,2}$, Manuel Pereira BARBOSA ${ }^{1,2}$ \\ Acta Med Port 2019 Nov;32(11):714-720 - https://doi.org/10.20344/amp.11893
}

ABSTRACT

Introduction: Hospitalizations due to angioedema are important especially in debilitating or life-threatening situations. The aim of this study was to evaluate the frequency and etiology of angioedema without urticaria in hospital admissions.

Material and Methods: The admissions between 2009 and 2013 in Centro Hospitalar Lisboa Norte with a diagnosis grouped under the ICD9 codes of angioedema were retrospectively analysed. The episodes of angioedema with urticaria were excluded. The admissions were categorized into 2 groups: A - hospitalizations motivated by the angioedema; B — hospitalizations in which the angioedema was an incidental finding.

Results: There were 169 hospitalizations (52\% females, $96 \%$ adults, mean age $52 \pm 20.8$ years), distributed by 23 hospital departments, $51 \%$ in the Immunoallergology department. The mean annual angioedema admission rate was $72 / 100000$. In $68 \%$ of the cases, angioedema was the cause for the admission; in $32 \%$ an incidental finding. In $38 \%$ there was upper airway involvement. The etiologies were: hereditary angioedema in $24 \%$, angiotensin converting enzyme inhibitor induced angioedema in $31 \%$, idiopathic angioedema in $21 \%$, thrombolysis induced angioedema in $13 \%$, nonsteroidal anti-inflammatory drug-induced angioedema in $5 \%$.

Discussion: The main etiology was angiotensin converting enzyme inhibitor angioedema, followed by hereditary angioedema and thrombolysis induced angioedema, and these findings concur with the international literature.

Conclusion: The mean annual angioedema admission rate was $72 / 100000$ and there was airway involvement in $38 \%$ of hospitalizations. Keywords: Angioedema; Angioedemas, Hereditary; Angiotensin-Converting Enzyme Inhibitors; Hospitalization

\section{RESUMO}

Introdução: Os internamentos por angioedema são importantes, sobretudo, nas situações incapacitantes ou de risco de vida. O objetivo deste estudo foi avaliar a frequência e etiologia dos internamentos por angioedema sem urticária.

Material e Métodos: Estudo retrospetivo dos internamentos com os códigos CID9 para angioedema, entre 2009 e 2013 , no Centro Hospitalar Lisboa Norte. Foram excluídos os episódios de angioedema com urticária. Categorizaram-se os internamentos em dois grupos: A - Internamentos motivados pela crise de angioedema; B - Internamentos em que o angioedema foi uma intercorrência. Resultados: Foram incluídos 169 internamentos (53\% mulheres, 96\% adultos, idade média $52 \pm 20,8$ anos), distribuídos por 23 serviços hospitalares (51\% na Imunoalergologia), com uma taxa média anual de internamentos de $72 / 100000$. Em 68\% o angioedema foi o motivo de internamento, em 32\% uma intercorrência. Em 38\% houve envolvimento das vias aéreas superiores. As etiologias foram: em $24 \%$ angioedema hereditário, em $31 \%$ angioedema induzido por inibidores da enzima conversora da angiotensina, $21 \%$ foram idiopáticos, em 13\% o angioedema surgiu após trombólise, em $5 \%$ induzido por anti-inflamatórios não esteroides e $7 \%$ outras etiologias. Discussão: A principal etiologia foi o angioedema induzido por inibidores da enzima conversora da angiotensina, seguido do angioedema hereditario e angioedema associado a trombolise, sendo estes dados semelhantes a outras revisões internacionais.

Conclusão: A taxa média de internamentos por angioedema foi de 72/100 000 e a frequência de envolvimento das vias aéreas foi de $38 \%$.

Palavras-chave: Angioedema; Angioedema Hereditário; Hospitalização; Inibidores da Enzima Conversora da Angiotensina

\section{INTRODUCTION}

Angioedema $(A E)$ is a self-limited, localized swelling of the deep dermis, subcutaneous or submucosal tissues due to vascular leakage. ${ }^{1}$ It was first described in 1876 by John Laws Milton, who, at the time, called it 'giant urticaria'. ${ }^{2}$ Later, in 1882, Heinriche Quincke defined this condition as angioneurotic edema. ${ }^{3}$

AE classification according to endotypes ${ }^{4,5}$ and phenotypes $^{6,7}$ is crucial for a correct diagnosis and therapeutic approach. Based on these, AE is classified as occurring 'with' or 'without' wheals. ${ }^{6}$ Angioedema with wheals is a hallmark of urticaria ${ }^{8,9}$ and can be acute or chronic, spontaneous or inducible. AE without wheals, on the other hand, may occur as a distinct entity and can be classified as histaminergic or non-histaminergic. ${ }^{4,7}$ The first group includes the acute allergic, the pseudo-allergic and the recurrent $A E$ forms. The non-histaminergic $A E$ group includes $A E$ induced by angiotensin-converting-enzyme inhibitor (ACEi), AE induced by nonsteroidal anti-inflammatory drugs (NSAID) and hereditary angioedema $(\mathrm{HAE})^{10}$ either with quantitative and/or qualitative complement deficiency (type I and type II HAE) or without complement deficiency (HAE with normal complement). ${ }^{11}$

Clinically, AE without urticaria can be acute or recurrent, have a spontaneous resolution or can be a life-threatening condition, if there is upper airway involvement and

1. Serviço de Imunoalergologia. Hospital de Santa Maria. Centro Hospitalar Universitário de Lisboa Norte. Lisboa. Portugal.

2. Clínica Universitária de Imunoalergologia. Faculdade de Medicina. Universidade de Lisboa. Lisboa. Portugal.

$\square$ Autor correspondente: Joana Cosme. joana.cosme@chln.min-saude.pt

Recebido: 05 de fevereiro de 2019 - Aceite: 17 de junho de 2019 | Copyright $\odot$ Ordem dos Médicos 2019 
risk of asphyxia. ${ }^{11-14}$ Therefore, hospital admission and subsequent inpatient hospitalization may be important for monitoring a potentially life-threatening situation and its response to treatment.

Additionally, abdominal attacks in HAE patients may also require special monitoring. They are caused by edema of the gastrointestinal wall, which can be very painful, simulating an 'acute abdomen'. ${ }^{15,16}$ In these circumstances, hospital admissions are important for clinical surveillance and to evaluate patients' response to specific and non-specific therapy.

$\mathrm{AE}$ can be the cause of an emergency department admission and lead to an inpatient hospitalization or can be an incidental situation during a hospitalization, as an adverse reaction to drugs such as $A C E i$, recombinant tissue plasminogen activator (rtPA), or NSAID. Besides this, HAE patients may need to be admitted for prophylactic therapy to prevent acute HAE attacks with plasma-derived C1-inhibitor (pdC1-INH), $1-2$ hours before an invasive procedure. These hospitalizations generally have a mean duration of 24 hours to allow for proper patient monitoring after the procedure.

There is international consensus for the diagnosis and approach of $\mathrm{AE}$ without wheals. ${ }^{15}$ However, in Portugal, the epidemiological characteristics of the inpatient hospitalizations for this type of $A E$ are unknown.

Thus, the objective of the present study is to evaluate the frequency of these hospitalizations and the etiology and clinical characteristics of the hospitalized patients with AE without wheals in the Centro Hospital Universitário de Lisboa Norte, in Lisbon.

\section{MATERIAL AND METHODS \\ Study design}

Retrospective analysis of hospital inpatient admissions between 2009 and 2013 with a diagnosis grouped under the broad categories of AE (ICD-9-CM codes 995.1: angioneurotic oedema and 277.6: other deficiencies of circulating enzymes) in the Centro Hospitalar Universitário de Lisboa Norte (CHULN). CHULN is a Portuguese public medical center that incorporates two university hospitals, Hospital de Santa Maria and Hospital Pulido Valente, both located in Lisbon. Clinical data from the patients from these two hospitals under these codes was reviewed. We only included cases of AE without associated wheals.

We excluded all the admissions coded with ICD9-codes 708 (urticaria) and 698.2 (pruritus and other associated conditions), all AE that were part of an anaphylactic episode and all situations that were incorrectly diagnosed as $A E$. Hereditary angioedema patients that needed to be hospitalized for prophylactic treatment administration before an invasive procedure were not included in this study.

The following data was recorded from patients' files: demographics (age, ethnicity and gender), AE characteristics (location, probable causal agent and other associated conditions), patients' previous therapy, hospitalization duration (number of days) and destination after discharge. According to the information described in the patients' file the existence or not of upper airway involvement (tongue or pharyngo-laryngeal $\mathrm{AE}$ ) was also considered. If the patient had clinical and/or laboratorial criteria of infection it was classified as having concomitant infection. Types 1 and 2 HAE diagnoses were made based on biochemical and functional levels of $\mathrm{C} 1 \mathrm{INH}$ found in patients' files. More than one episode of hospitalization was allowed per patient. Hospitalizations with at least 24-hour duration were considered.

The authors distinguished 2 groups: A - patients in which $A E$ was the reason for admission; $B$ - patients that had an $A E$ as an incidental situation that appeared during admission due to another clinical condition.

The study protocol was approved by the ethics committee of CHULN and the confidentiality of all data was assured.

\section{Statistical analysis}

Statistical analysis was performed using a software SPSS version 24 for Windows. Absolute frequencies and percentages were used to characterize categorical variables while mean and standard deviation were used to describe continuous variables. The rate of hospitalizations per year was determined by dividing the number of hospitalizations due to $A E$ without urticaria by the total number of hospitalizations that occurred in the CHULN in the same year. The authors also determined the mean hospitalization rate for angioedema between 2009 and 2013 as the average of the 5-year rates. Monte Carlo estimate of Fisher's exact test was used for statistical analysis, except for comparisons between the means where we used the Kruskal-Wallis test. A $p$ value $<0.05$ was considered statistically significant.

\section{RESULTS}

Between 2009 and 2013 there were 209 hospitalizations in the CHULN that received an angioedema ICD9 code. Only 169 episodes were included. A total of 8 miscoded episodes and 32 admissions to administer prophylactic therapy in hereditary angioedema patients were excluded. Table 1 summarizes the clinical and demographic characteristics from the inpatient hospital admissions. Eightyseven $(51.5 \%)$ patients were female, $162(96 \%)$ were adults and the mean age was 52 years old. Regarding ethnicity 114 (67.5\%) were Caucasian, 35 (20.7\%) had an African origin and in $20(11.8 \%)$ other ethnicities or no information regarding ethnicity in the patients' files.

The mean duration of hospitalization was 5.9 days ( $\max$ 69 days, min 1 day), there were no fatalities and $62 \%$ were referred to the allergy unit outpatient clinic after hospital discharge. Eighty-seven (51.5\%) of the inpatient admissions took place in the Immunoallergology department hospitalization ward, with the remaining patients having been distributed by 23 different CHULN departments/units.

Table 2 shows the number of inpatient hospital admissions per year for $A E$ as well as the overall number of CHULN inpatient admissions, between 2009 and 2013. According to this data, in 2009 the rate of hospitalized patients for AE in CHULN was 53.9 per 100000 and in 2013 
Table 1 - Demographic and clinical characteristics of the population

\begin{tabular}{lc}
\hline Demographic and clinical characteristics of the population \\
\hline Characteristics & $\mathbf{N}^{\circ}$ patients (\%) \\
\hline Number of patients & $169(100)$ \\
Age (years) & \\
mean \pm SD & $52 \pm 20$ \\
$<1$ & $0(0)$ \\
$1-4$ & $0(0)$ \\
$5-9$ & $2(1.2)$ \\
$10-14$ & $2(1.2)$ \\
$15-24$ & $10(5.9)$ \\
$25-44$ & $45(26.6)$ \\
$45-64$ & $49(29)$ \\
$65-74$ & $29(17.2)$ \\
$75-84$ & $31(18.3)$ \\
$>85$ & $11(6.5)$ \\
Adults & $162(96)$ \\
Children (<18 years) & $7(4)$ \\
Gender & \\
Female & $87(51.5)$ \\
Male & $82(48.5)$ \\
Ethnicity & \\
Caucasian & $114(67.5)$ \\
African origin & $35(20.7)$ \\
Other/non-specified & $20(11.8)$ \\
Hospitalization days & \\
Mean \pm SD & $5.9 \pm 4.9$ \\
Hospitalization site & \\
Immunoallergology Department & $87(51.5)$ \\
Another department & \\
\hline &
\end{tabular}

SD: standard deviation

reached 70.5 per 100000 , with the mean value of hospitalizations for angioedema being 71.6 per 100000 hospitalizations in CHULN in the 5-year period of the study.

In 115 (68\%) inpatient admissions, AE was the main reason for the patient admission; in 54 (32\%) AE was an incidental situation that occurred during admission (Table 3).
The most common reason for $A E$ inpatient admissions was ACEi induced AE in 52 (30.8\%) followed by HAE ( $n=40 ; 23.7 \%$ ), AE associated with thrombolysis in $22(13 \%)$ hospitalized patients, AE induced by NSAID in $8(4.7 \%)$ hospitalizations, $A E$ induced by other less frequent situations (antibiotics or antifungal drugs or infection) in $12(7.1 \%)$ and in $35(20.7 \%)$ admission episodes the AE was classified as idiopathic $(p=0.58)$. In all the hospital inpatient admissions that occurred in children (4\%), the AE etiology was HAE. The number of hospitalizations due to HAE slightly increased over the years, while the number of idiopathic AE hospitalizations decreased from 2012 to 2013. For the remaining etiologies the number of hospitalizations over the years was similar.

There were no statistically significant differences regarding age $(p=0.07)$ between all causes of AE. In general, a predominance of females $(p=0.01)$ and a predominance of Caucasian patients $(p<0.0001)$ was observed in almost all etiologies, with few exceptions - Table 4.

Regarding the AE location, there was upper airway (tongue, pharynx, larynx) involvement in 64 cases (38\%), either as an isolated location or associated with another $\mathrm{AE}$ site involvement (Table 5). Airway intubation was required in two hospitalizations, both due to rtPA induced AE. In HAE admissions, the abdominal location was the most frequently involved site, and the face, the lips and the upper airway (tongue or pharyngo-laryngeal) were the most frequent locations (Table 5) in both ACEi or rTPA induced AE.

\section{Angiotensin converting enzyme inhibitor induced angioedema}

Considering the 169 AE hospitalizations, ACEi induced $\mathrm{AE}$ was the most frequent etiology.

Fifty-two inpatient hospital admissions were due to ACEi induced AE (65\% females, $27 \%$ were Caucasian and $73 \%$ had an African origin, mean age \pm SD $67 \pm 15.2$ years).

Table 2 - Total of hospitalizations and angioedema without urticaria hospitalizations, between 2009 and 2013

\begin{tabular}{|c|c|c|c|c|c|c|c|}
\hline & 2009 & 2010 & 2011 & 2012 & 2013 & Total & Mean \\
\hline Hospitalizations with angioedema without urticaria $-\mathrm{n}$ & 27 & 30 & 42 & 40 & 30 & 169 & 33.8 \\
\hline$A-A E$ as a cause for the hospitalization & 15 & 17 & 32 & 30 & 17 & 111 & 22 \\
\hline $\mathrm{B}-\mathrm{AE}$ as an incidental situation & 12 & 13 & 10 & 10 & 13 & 58 & 12 \\
\hline Total of hospitalizations in the CHULN $-n$ & 50128 & 49091 & 48844 & 46265 & 42544 & - & 47374 \\
\hline $\begin{array}{l}\text { Rate of hospitalizations for angioedema without urticaria } \\
\text { per } 100,000 \text { hospitalizations }\end{array}$ & 53.9 & 61.1 & 86 & 86.5 & 70.5 & - & 71.6 \\
\hline$A-A E$ as a cause for the hospitalization & 29.9 & 34.6 & 65.5 & 64.8 & 40 & - & 46.9 \\
\hline $\mathrm{B}-\mathrm{AE}$ as an incidental situation & 23.9 & 26.5 & 20.5 & 21.6 & 30.6 & - & 24.6 \\
\hline
\end{tabular}

AE: angioedema; HAE: hereditary angioedema

Table 3 - Distribution of hospitalization episodes

\begin{tabular}{lccccccc}
\hline \multirow{2}{*}{ Groups of angioedema } & \multicolumn{7}{c}{ Etiologies } \\
\cline { 2 - 7 } & HAE & ACEi-AE & rtPA-AE & NSAID-AE & Other & Idiopathic & Total - $\mathbf{n}(\%)$ \\
\hline A - AE as a cause for the hospitalization & 39 & 34 & 0 & 6 & 8 & 24 & $115(68)$ \\
B - AE as an incidental situation & 1 & 18 & 22 & 2 & 4 & 11 & $54(32)$ \\
Total - $\mathbf{n}(\%)$ & $\mathbf{4 0 ( 2 3 . 7 )}$ & $\mathbf{5 2 ( 3 0 . 8 )}$ & $\mathbf{2 2 ( 1 3 )}$ & $\mathbf{8 ( 4 . 7 )}$ & $\mathbf{1 2}(\mathbf{7 . 1})$ & $\mathbf{3 5 ( 2 0 . 7 )}$ & $\mathbf{1 6 9}(\mathbf{1 0 0})$ \\
\hline
\end{tabular}

AE: angioedema; ACEi-AE: angiotensin-converting-enzyme inhibitor induced angioedema; HAE: hereditary angioedema; rTPA-AE: recombinant tissue plasminogen activator induced angioedema; NSAID-AE: nonsteroidal anti-inflammatory drugs induced angioedema; Other: other etiologies. 
Table 4 - Demographic characteristics of hospitalizations according to etiology

\begin{tabular}{lccccccc}
\hline & $\begin{array}{c}\text { ACEI-AE } \\
(\mathbf{n}=\mathbf{5 2})\end{array}$ & $\begin{array}{c}\text { HAE } \\
(\mathbf{n}=\mathbf{4 0})\end{array}$ & $\begin{array}{c}\text { AE-rTPA } \\
(\mathbf{n}=\mathbf{2 2})\end{array}$ & $\begin{array}{c}\text { NSAID-AE } \\
(\mathbf{n}=\mathbf{8})\end{array}$ & $\begin{array}{c}\text { Other } \\
(\mathbf{n}=\mathbf{1 2})\end{array}$ & $\begin{array}{c}\text { Idiopathic } \\
(\mathbf{n}=\mathbf{3 5})\end{array}$ & $\begin{array}{c}\mathbf{p} \text {-value } \\
\text { Mean age (years) }\end{array}$ \\
\hline 67 & 37 & 68.5 & 52.5 & 56 & 58.6 & 0.07 \\
Female (\%) & 65 & 57.5 & 36 & 50 & 75 & 43 & 0.01 \\
Caucasian (\%) & 27 & 98 & 77 & 75 & 100 & 77 & $<0.0001$ \\
\hline
\end{tabular}

AE: angioedema; ACEi-AE: angiotensin-converting-enzyme inhibitor induced angioedema; HAE: hereditary angioedema; rTPA-AE: recombinant tissue plasminogen activator induced angioedema; NSAID-AE: nonsteroidal anti-inflammatory drugs induced angioedema; Other: other etiologies

In patients with $A C E i$ induced $A E$ the timing in which the patient started being treated with an ACEi was revised. One patient was on ACEi for more than 10 years, 11 (21.2\%) had been taking an ACEi between 10 years to 6 months and $10(19.2 \%)$ had been taking ACEi for less than 6 months. Two cases (3.8\%) corresponded to situations of patients with previous indication for ACEi avoidance that had a subsequent ACEi administration in the emergency department for a hypertensive crisis. In 28 hospitalizations (53.8\%) there was no data in the clinical file regarding the period during which patients were taking ACEi. According to the data in the clinical file, the most commonly involved ACEi was captopril $(29 \%)$, followed by perindopril $(25 \%)$, enalapril $(19 \%)$, lisinopril (17\%), ramipril (6\%) and cilazapril (4\%).

\section{Hereditary angioedema}

HAE was the second most frequent etiology. Within the 40 hospitalization episodes $82.5 \%$ were adults, $57.5 \%$ were females, $98 \%$ Caucasians, mean age \pm SD was $37 \pm 15$ years. Seventeen $(42.5 \%)$ of the hospitalizations were of type I HAE, while $23(57.5 \%)$ of type II HAE and there were no patients with HAE with normal complement levels.

In $39(97.5 \%)$ of these hospitalizations the AE attack was the cause of hospitalization. The reported triggers for the HAE crises were stress (26\%), therapeutic non-adherence $(10 \%)$, infection ( $8 \%)$, extreme physical exercise
(3\%), ACEi therapy (3\%). In $21 \%$ there was no reported trigger. The abdomen was the most frequent location for HAE attacks. All patients were subjected to an abdominal ultrasonography, but abdominal involvement was only documented in 6 patients (ascites and intestinal wall edema were found in 5 patients and in 1 patient only minimal peritoneal fluid was identified).

\section{Thrombolysis induced angioedema}

There were 22 cases with rPA induced AE $(36 \%$ females, $77 \%$ Caucasian, mean age \pm SD $68.5 \pm 12.8$ years) and all episodes corresponded to patients that were hospitalized due to an acute stroke. In these, three subsets of patients were found: the first $(37 \%)$ in which $A E$ appeared within the first 8 hours after rtPA in patients with no previous history of ACEi intake, the second (37\%) that corresponded to the situations of hypertensive patients previously treated with ACEi who underwent rtPA and developed AE; and the third group (26\%) in which patients received rtPA and had also received ACEi concomitantly during the procedure due to a hypertensive crisis. The most frequent location was the tongue with unilateral angioedema of the tongue (ipsilateral to the stroke site).

There was upper airway involvement in 13 patients and 2 of these required airway intubation. These 2 patients that required intubation had been prescribed an ACEi due to a

Table 5 - Location of angioedema without urticaria attacks

\begin{tabular}{|c|c|c|c|c|c|c|c|}
\hline \multirow[b]{2}{*}{ AE attacks location } & \multicolumn{7}{|c|}{ Etiologies } \\
\hline & $\begin{array}{l}\text { Total } \\
\mathrm{n}(\%)\end{array}$ & $\begin{array}{l}\text { HAE } \\
\mathrm{n}(\%)\end{array}$ & $\begin{array}{c}\text { ACEi-AE } \\
n(\%)\end{array}$ & $\begin{array}{c}\text { rTPA-AE } \\
\text { n (\%) }\end{array}$ & $\begin{array}{c}\text { NSAID-AE } \\
n(\%)\end{array}$ & $\begin{array}{l}\text { Other } \\
\mathrm{n}(\%)\end{array}$ & $\begin{array}{c}\text { Idiopathic } \\
\mathrm{n}(\%)\end{array}$ \\
\hline \multicolumn{8}{|l|}{ One location site } \\
\hline Face & $27(16)$ & $6(15)$ & $0(0)$ & $4(18)$ & $4(50)$ & $5(42)$ & $10(29)$ \\
\hline Lips & 26 (15) & $0(0)$ & $12(23)$ & $5(23)$ & $1(12.5)$ & $4(33)$ & $4(11)$ \\
\hline Tongue & $33(20)$ & $1(3)$ & $13(25)$ & $9(41)$ & $0(0)$ & $3(25)$ & $5(14)$ \\
\hline Pharyngolaryngeal & $13(8)$ & $4(10)$ & 7 (13) & $0(0)$ & $2(25)$ & $0(0)$ & $0(0)$ \\
\hline Cervical & $9(5)$ & $7(18)$ & $0(0)$ & $0(0)$ & $0(0)$ & $0(0)$ & $0(0)$ \\
\hline Peripheral & $6(4)$ & $6(15)$ & $0(0)$ & $0(0)$ & $0(0)$ & $0(0)$ & $0(0)$ \\
\hline Abdominal & $12(7)$ & $12^{*}(30)$ & $0(0)$ & $0(0)$ & $0(0)$ & $0(0)$ & $0(0)$ \\
\hline \multicolumn{8}{|l|}{ Multi location site } \\
\hline Face + Lips & $19(11)$ & $3(8)$ & $12(23)$ & $0(0)$ & $1(12.5)$ & $0(0)$ & $4(11)$ \\
\hline Lips + Tongue & $10(6)$ & $0(0)$ & $6(12)$ & $2(9)$ & $0(0)$ & $0(0)$ & $3(9)$ \\
\hline Face + Cervical & $5(3)$ & $0(0)$ & $0(0)$ & $0(0)$ & $0(0)$ & $0(0)$ & $5(14)$ \\
\hline Tongue + Pharyngolaryngeal & $8(5)$ & $0(0)$ & $2(4)$ & $2^{\star \star}(9)$ & $0(0)$ & $0(0)$ & $4(11)$ \\
\hline Abdominal + Peripheral & $1(1)$ & $1(3)$ & $0(0)$ & $0(0)$ & $0(0)$ & $0(0)$ & $0(0)$ \\
\hline TOTAL & $169(100)$ & $40(100)$ & $52(100)$ & $22(100)$ & $8(100)$ & $12(100)$ & $35(100)$ \\
\hline
\end{tabular}

${ }^{*}$ In $6(50 \%)$ the abdominal AE was documented by ultrasonography; ${ }^{* *}$ The 32 hospitalizations for AE prophylaxis are not included in these as there were no AE crisis. • Airway intubation was required.

HAE: Hereditary angioedema; ACEi-AE: angiotensin-converting-enzyme inhibitor induced angioedema; rTPA-AE: thrombolysis induced angioedema; NSAID$\mathrm{AE}$ : nonsteroidal anti-inflammatory drugs induced angioedema; Other: other etiologies 
hypertensive crisis during the thrombolysis procedure and had no previous history of ACEi intake.

\section{Nonsteroidal anti-inflammatory drug induced angioedema}

In 8 admissions NSAID was the etiological factor considered (50\% females, $75 \%$ Caucasian, mean age \pm SD 52.5 \pm 11.5 years). Ibuprofen was involved in $4(50 \%)$, naproxen in $2(25 \%)$, diclofenac in $1(25 \%)$ and etoricoxib in $1(12.5 \%)$. No infection criteria were established in these admissions.

\section{Other etiologies and idiopathic angioedema}

In the group named 'other etiologies' we included 12 hospitalization episodes (75\% females, $100 \%$ Caucasian, mean age \pm SD $56 \pm 18.5$ years) probably associated with antibiotics or antifungal drugs (75\%) and probably due to infection (25\%) without any associated drug.

In 35 hospitalizations (43\% females, $77 \%$ Caucasian, mean age \pm SD $58.6 \pm 20.8$ years), no etiology for angioedema was established in the patients' medical record and were classified as idiopathic AE attacks.

\section{DISCUSSION}

This study describes the results of the first retrospective analysis carried out in Portugal regarding admissions due to $A E$ without associated urticaria. Over the last few years, interest in the pathophysiology and clinical manifestations of this form of AE has increased. However, little is known about the epidemiology and characteristics of the hospitalizations for this form of $A E$.

Between 2009 and 2013, there were 169 inpatient hospitalization episodes due to AE without urticaria and in $65.7 \%$ of these the AE attack was the reason for the hospitalization, and in $34.3 \% \mathrm{AE}$ was an incidental condition occurring during hospitalization. Overall, we documented an annual average hospitalization rate of 46.9 per 100000 for the hospitalizations motivated by the $\mathrm{AE}$ attack and a rate of 24.6 per 100000 for the hospitalizations in which the $A E$ attack occurred in patients hospitalized for other reasons.
The number of hospitalizations for AE slightly increased between 2011 and 2012 mainly due to HAE hospitalizations. This aspect can be justified by the fact that CHULN is a reference center for HAE.

Regarding the 111 hospitalizations that were motivated by the $A E$ attack, the most frequent reason was $\mathrm{HAE}$ $(n=39 ; 35 \%)$ followed by ACEi induced AE ( $n=34 ; 31 \%$ ) and by idiopathic $A E$ episodes $(n=35 ; 17 \%)$. Mansi et al, ${ }^{16}$ in a review of 1058 hospitalizations episodes due to $\mathrm{AE}$ without urticaria, between 1993 and 2012, in a tertiary hospital, found a frequency of hospitalizations due to HAE similar to ours (36\%). However, in the Mansi et a/ ${ }^{15}$ study, the most frequent etiology was idiopathic $\mathrm{AE}(42 \%)$ and $\mathrm{ACEi}$ induced $A E$ was the third most frequent etiology (27\%). These findings are also in line with the study by Malbrán et $a l,{ }^{17}$ that characterized 280 hospitalization episodes due to $A E$ without urticaria and found that idiopathic $A E$ was the most frequent etiology (55.7\%) followed by drug induced $A E$ episodes (24.3\%) and by HAE in $15.7 \%$ of the cases. In our opinion, the high frequency of HAE in our population may be explained by the fact that CHULN is a national reference center for the follow-up of patients with this disease.

Considering the hospitalizations that were motivated by other conditions and in which AE occurred as an incidental situation, $33.8 \%$ corresponded to idiopathic $\mathrm{AE}, 31 \%$ to rtPA induced $A E$ and $25 \%$ to ACEi induced $A E$.

rtPA is a therapeutic option after an acute stroke. ${ }^{18}$ However, between $1.3 \%$ and $5 \%$ of patients treated with rt-PA after a stroke may develop AE. ${ }^{19} \mathrm{AE}$ associated with the administration of rtPA generally appears as unilateral and painless edema of the lips, tongue and face, 30 to 120 minutes after the beginning of rtPA administration. ${ }^{19}$

An aspect to be emphasized in our study is that in $63 \%$ of the patients with rTPA induced AE there was a history of concomitant prescription of ACEi. It is estimated that $\mathrm{AE}$ occurs in $0.1 \%-2.2 \%$ of patients treated with $\mathrm{ACEi}^{20}$ but this frequency may rise given that these drugs are increasingly being used. ACEi induced angioedema is more

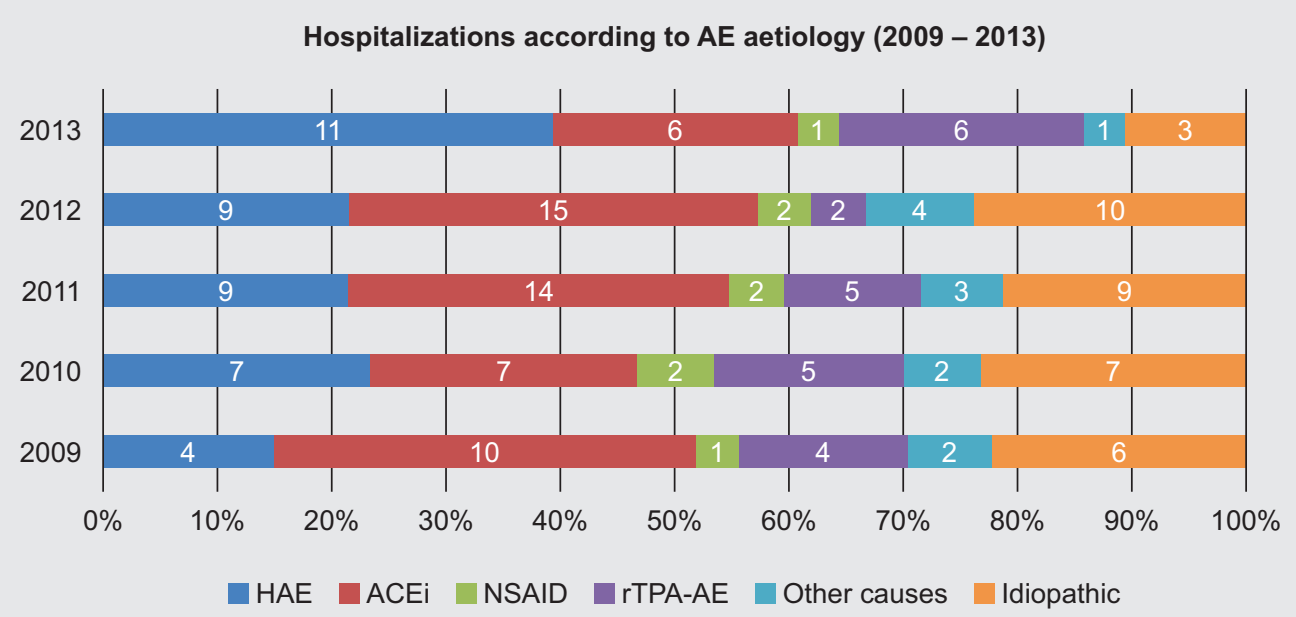

Figure 1 - Number of hospitalizations per year according to angioedema etiology between 2009 to 2013

$\mathrm{AE}$ : angioedema; ACEi-AE: angiotensin-converting-enzyme inhibitor induced angioedema; HAE: hereditary angioedema; rTPA-AE: recombinant tissue plasminogen activator induced angioedema; NSAID-AE: nonsteroidal anti-inflammatory drugs induced angioedema; Other: other etiologies 
common in females and in patients with a black origin ${ }^{19,20}$ as it is pointed out in our study. Studies prior to ours describe a frequency of $30 \%-38 \%$ of emergency admissions due to ACEi induced AE. ${ }^{21}$ However, only a few of these cases require inpatient hospitalization for surveillance and therapy. ${ }^{22}$ Bonner et $a^{23}$ recently proposed an ACEi induced AE classification scale and clinical discharge criteria based on the symptoms of airway involvement. In this classification, the main criteria for hospitalization is the existence of airway edema or the evidence of edema rapid progression to the airways. ${ }^{24}$ Banerji et al, ${ }^{22}$ however, consider that it is advisable to monitor elderly patients with ACEi induced AE in order to improve their comfort. In our study, we found that patients with $A C E i$ induced $A E$ were older compared to patients with other etiologies such as patients with HAE or NSAIDinduced AE. Therefore, we believe that the fact that elderly patients have more co-morbidities and a higher risk of serious adverse drug reactions may justify the high number of hospitalizations for ACEi induced AE in our population.

Emergency admissions and inpatient hospitalizations may be important for monitoring of symptoms and treatment response, especially in life-threatening conditions such as upper airway edema. In our study, tongue, pharynx or larynx involvement was found in $38 \%$ of the AE episodes. Javaud et $a^{25}$ reviewed all the hospitalizations motivated by HAE that occurred in France, between January 2011 and December 2013 (29 patients, 50 attacks) and found that the main risk factors for AE hospitalization were face and larynx involvement and less frequently abdominal crisis. In our study, abdominal attacks had a similar frequency (32.5\%) to face and upper airway attacks (35\%), within HAE hospitalized patients.

Abdominal symptoms occur in about $70 \%$ to $80 \%$ of $\mathrm{HAE}$ patients. ${ }^{26,27}$ Abdominal $A E$ attacks are generally associated with severe abdominal pain, nausea, vomiting and diarrhea. Ascites may also occur due to the existence of intestinal wall edema and increased vascular permeability that leads to extravasation of plasma in the peritoneal cavity. ${ }^{27,28}$ In rare cases, these attacks may also be associated with hypovolemia. ${ }^{27}$ For this reason, hospitalizations are important in order to ensure a faster symptomatic relief through the administration of specific and non-specific therapies and for clinical monitoring. In our population, patients with abdominal AE crisis underwent abdominal and pelvic ultrasound and in $50 \%$ of these patients' intestinal wall edema was documented. Pedrosa et $a^{29}$ considered that abdominal ultrasound is a cost-effective, reliable and reproducible diagnostic method and important for a correct diagnosis.

Our study has, however, some limitations. The first is related to its retrospective design. As we retrospectively

\section{REFERENCES}

1. Kalan AP, Greaves MW. Angioedema. J Am Acad Dermatol. 2005;53:373-88.

2. Milton JL. On giant urticaria. Edinb Med J. 1876;22:513-26.

3. Quincke $\mathrm{H}$. Uber akutes umschriebened hautodem. Monatshe Prakt Dermatol. 1882;1:129-31.

4. Giavina-Bianchi P, Aun MV, Motta AA, Kalil J, Castells M. Classification of angioedema by endotypes. Clin Exp Allergy. 2015;45:1142-3. reviewed all the hospitalizations coded with the ICD9 codes for AE during a 5-year period, it is not possible to establish, with great precision, an evolutionary curve of hospitalizations given the short period of time considered. Secondly, our analysis may be limited to the fact that we only considered data from patients' clinical files as there is undoubtedly some variability in the records, especially concerning $A E$ location. We attempted to overcome this limitation by having two authors of our study independently analyzing the data. Thirdly, no information about the treatment used for the different $A E$ etiologies was analyzed. In our opinion, this information may be necessary for further studies, in order to establish precise hospitalization and clinical discharge criteria to be adopted in national guidelines.

\section{CONCLUSION}

This is the first study carried out in Portugal that analyzes the frequency of hospitalizations for AE without associated urticaria, and which documented an average annual rate of AE inpatient hospitalizations of 71.6 per 100000 hospitalizations, with upper airway (tongue, larynx and pharynx) involvement in $38 \%$ of the episodes.

We found that, in most hospitalizations, the AE attack was the reason that led to hospitalization, which highlights the nature of this clinical condition. The main etiology of $A E$ attacks was HAE, followed by ACEi induced $A E$ and idiopathic $A E$. AE also occurred as an incidental condition in hospitalizations motivated by other causes, and in these patients AE attacks occurred mainly associated with administration of ACEi and rtPA.

\section{PROTECTION OF HUMANS AND ANIMALS}

The authors declare that the procedures were followed according to the regulations established by the Clinical Research and Ethics Committee and to the Helsinki Declaration of the World Medical Association.

\section{DATA CONFIDENTIALITY}

The authors declare having followed the protocols in use at their working center regarding patients' data publication.

\section{CONFLICTS OF INTEREST}

The authors declare that they have no conflicts of interest related with the present work.

\section{FUNDING SOURCES}

This work did not receive any type of financial support of any entity in the public or private domain.

5. Suffritti C, Zanichelli A, Maggioni L, Bonanni E, Cugno M, Cicardi M. High-molecular-weight kininogen cleavage correlates with disease states in the bradykinin-mediated angioedema due to hereditary C1inhibitor deficiency. Clin Exp Allergy. 2014;44:1503-14.

6. Aberer W. Angioedema is not just "deep urticaria" but an entity of its own. Allergy. 2014;69:549-52.

7. Wu MA, Perego F, Zanichelli A, Cicardi M. Angioedema phenotypes: 
disease expression and classification. Clin Rev Allergy Immunol. 2016;51:162-9.

8. Costa C, Gonçalo M, GPEU - Grupo Português de Estudos de Urticária. Diagnostic and therapeutic approach of chronic spontaneous urticaria: Recommendations in Portugal. Acta Med Port. 2016;29:763-81.

9. Zuberbier T, Aberer W, Asero R, Abdul Latiff AH, Baker D, BallmerWeber $B$, et al. The EAACI/GA²LN/EDF/WAO guideline for the definition, classification, diagnosis and management of urticaria. Allergy. 2018;73:1393-414.

10. Maurer $M$, Magerl $M$, Ansotegui I, Aygören-Pürsün $E$, Betschel $S$, Bork $\mathrm{K}$. The international WAO/EAACI guideline for the management of hereditary angioedema-The 2017 revision and update. Allergy. 2018;73:1575-96.

11. Bernstein JA, Lang DM, Khan DA, Craig T, Dreyfus D, Hsieh F, et al. The diagnosis and management of acute and chronic urticaria: 2014 update. J Allergy Clin Immunol 2014;133:1270-7.

12. Pedrosa M, Prieto-García A, Sala-Cunill A. Management of angioedema without urticaria in the emergency department. Ann Med. 2014;46:607-18.

13. Bernstein JA, Moellman J. Emerging concepts in the diagnosis and treatment of patients with undifferentiated angioedema. Int J Emerg Med. 2012;5:39.

14. Cicardi M, Bellis P, Bertazzoni G, Cancian M, Chiesa M, Cremonesi P. Guidance for diagnosis and treatment of acute angioedema in the emergency department: consensus statement by a panel of Italian experts. Intern Emerg Med. 2014;9:85-92.

15. Caballero $T$, Baeza $M L$, Cabañas $R$, Campos $A$, Cimbollek $S$, Gómez-Traseira C, et al. Consensus statement on the diagnosis, management, and treatment of angioedema mediated by bradykinin. Part I. Classification, epidemiology, pathophysiology, genetics, clinical symptoms, and diagnosis. J Investig Allergol Clin Immunol. 2011;21:333-47.

16. Mansi M, Zanichelli A, Coerezza A, Suffritti C, Wu MA, Vacchini R, et al Presentation, diagnosis and treatment of angioedema without wheals: a retrospective analysis of a cohort of 1058 patients. J Intern Med. 2015;277:585-93.

17. Malbrán E, Fernández Romero D, Juri MC, Larrauri BJ, Malbrán A. Epidemiology of angioedema without wheals in an allergy and immunology center. Medicina. 2015;75:273-6.

18. Bluhmki E, Chamorro A, Dávalos A, Machnig T, Sauce C, Wahlgren $\mathrm{N}$, et al. Stroke treatment with alteplase given 3.0-4.5 h after onset of acute ischaemic stroke (ECASS III): additional outcomes and subgroup analysis of a randomised controlled trial. Lancet Neurol. 2009;8:1095-102.

19. Fugate JE, Kalimullah EA, Wijdicks EF. Angioedema after tPA: what neurointensivists should know. Neurocrit Care. 2012;16:440-3.

20. Vleeming $W$, van Amsterdam JG, Stricker $B H$, de Wildt DJ. ACE inhibitor-induced angioedema. Incidence, prevention and management. Drug Saf. 1998;18:171-88.

21. Holm JP, Ovesen T. Increasing rate of angiotensin-converting enzyme inhibitor-related upper airway angio-oedema. Dan Med J. 2012;59:A4449.

22. Banerji A, Clark S, Blanda M, LoVecchio F, Snyder B, Camargo CA Jr. Multicenter study of patients with angiotensin-converting enzyme inhibitor-induced angioedema who present to the emergency department. Ann Allergy Asthma Immunol. 2008;100:327-32.

23. Bonner N, Panter C, Kimura A, Sinert R, Moellman J, Bernstein JA Development and validation of the angiotensin-converting enzyme inhibitor $(\mathrm{ACEI})$ induced angioedema investigator rating scale and proposed discharge criteria. BMC Health Serv Res. 2017;17:366.

24. Gang C, Lindsell CJ, Moellman J, Sublett W, Hart K, Collins S, et al. Factors associated with hospitalization of patients with angiotensinconverting enzyme inhibitor-induced angioedema. Allergy Asthma Proc. 2013;34:267-73

25. Javaud N, Gompel A, Bouillet L, Boccon-Gibod I, Cantin D, Smaiti $\mathrm{N}$, et al. Factors associated with hospital admission in hereditary angioedema attacks: a multicenter prospective study. Ann Allergy Asthma Immunol. 2015;114:499-503.

26. Colen N, Sharon A, Golik A, Zaidestein R, Modai D. Hereditary angioneurotic edema with severe hypovolemic shock. J Clin Gastroenterol. 1993;116:237-39.

27. Jolles S, Williams P, Carne E, Mian H, Huissoon A, Wong G, et al. A UK national audit of hereditary and acquired angioedema. Clin Exp Immunol. 2014;175:59-67.

28. Caballero T, Maurer M, Longhurst HJ, Aberer W, Bouillet L, Fabien V, et al. Triggers and prodromal symptoms of angioedema attacks in patients with hereditary angioedema. J Investig Allergol Clin Immunol. 2016;26:383-6.

29. Pedrosa M, Caballero T, Gómez-Traseira C, Olveira A, LópezSerrano C. Usefulness of abdominal ultrasonography in the follow-up of patients with hereditary C1-inhibitor deficiency. Ann Allergy Asthma Immunol. 2009:102:483-6. 